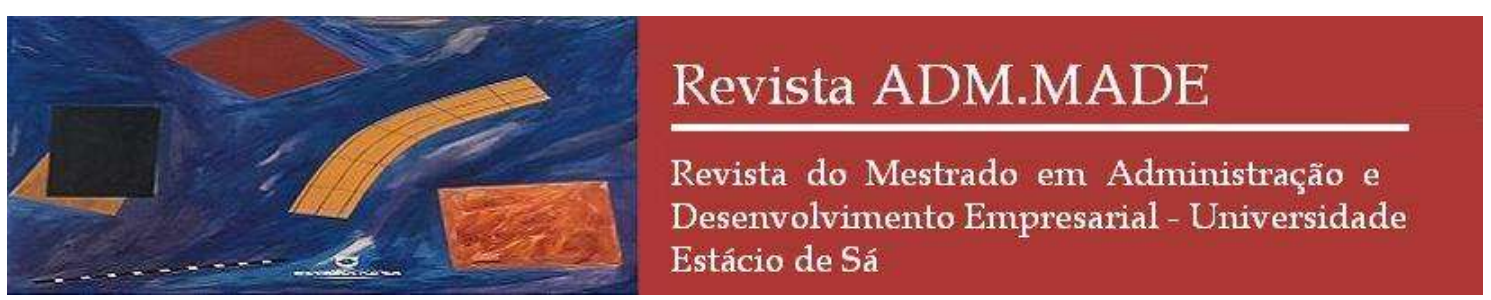

Revista ADM.MADE, Rio de Janeiro, ano 16, v.20, n.2, p.1-22, maio/agosto, 2016 http://dx.doi.org/10.21714/2237-51392016v20n2p001022

Revista do Mestrado em Administração e Desenvolvimento Empresarial da Universidade

Estácio de Sá - Rio de Janeiro (MADE/UNESA). ISSN: 2237-5139

Conteúdo publicado de acesso livre e irrestrito, sob licença Creative Commons 3.0. Editor responsável: Marco Aurélio Carino Bouzada

\title{
Internacionalização dos Programas de Pós-Graduação Stricto Sensu em Administração no Brasil
}

\author{
Flávia Braga Chinelato ${ }^{1}$ \\ Fabricio Ziviani ${ }^{2}$
}

Artigo recebido em 29/08/2016 e aprovado em 10/10/2016. Artigo avaliado em double blind review.

1 Doutoranda em Administração pela Universidade FUMEC. Professora na pós-graduação do Centro Universitário UMA. Endereço: Universidade FUMEC, Faculdade de Ciências Econômicas, Administrativas e Contábeis. Avenida Afonso Pena - de 3002 ao fim - lado par. Cruzeiro. CEP 30130-009 - Belo Horizonte, MG Brasil. Email: flaviachinelato@gmail.com.

${ }^{2}$ Doutor em Ciência da Informação pela Universidade Federal de Minas Gerais. Professor do Programa de PósGraduação em Sistemas de Informações e Gestão do Conhecimento da Universidade FUMEC.

Endereço: Universidade FUMEC, Faculdade de Ciências Econômicas, Administrativas e Contábeis. Avenida Afonso Pena - 3880 - Cruzeiro. CEP 30130-009 - Belo Horizonte, MG - Brasil. Email: fazist@hotmail.com. 


\section{Internacionalização dos Programas de Pós-Graduação Stricto Sensu em Administração no Brasil}

A teoria da internacionalização é muito aplicada a empresas, entretanto é possível empregá-la também em outras áreas, como a de ensino. Com o crescimento da competitividade, as universidades precisam ampliar seu campo de atuação, e a internacionalização pode ser uma importante estratégia para auxiliá-las nesta tarefa. Enfocando os programas de pós-graduação stricto sensu em Administração avaliados no triênio 2010-12 com notas 6 e 7 pela CAPES - os únicos considerados com elevado grau de internacionalização - a presente pesquisa verifica em que medida o grau de internacionalização desses programas reflete seu desempenho geral. O método utilizado é a de métodos múltiplos, sendo que, para a construção do banco de dados, foram extraídas informações do site da CAPES e de currículos Lattes. Verificou-se que não há uma padronização na maneira como os programas informam suas ações de internacionalização, e que não há um elevado alcance de cumprimento de todos os indicadores de internacionalização propostos pela CAPES. No total, os quatro programas alcançaram apenas 10 dos 14 indicadores propostos pela CAPES, o que corresponde a $71,5 \%$ dos indicadores.

Palavras-chave: Internacionalização do Ensino. Stricto Sensu. Administração. Pós- Graduação.

Keywords: Internationalization of Education. Stricto Sensu. Administration. Post-Graduation.

\section{Internationalization of Graduate Stricto Sensu Programs in Management in Brazil}

The theory of internationalization has a wide application to companies, however it is also possible to apply it in other areas such as education. With competition growing among universities, internationalization can become an important strategy to expand their field of action. This research focuses on postgraduate in Administration courses with grades 6 or 7 CAPES (a government agency) in the triennium 2010-2012. These grades are applicable only to programs with high degrees of internationalization. The present study aims to verify to what extent the degree of internationalization reflects the overall performance of the programs. Multiple methods were used in this study. The information needed to build a data base was extracted from two Brazilian sites: CAPES and Lattes. It became evident that there was no standardization on the way programs give information about their internationalization acts. Also from the 14 indicators created by CAPES, programs reached only 10 , which corresponds to $71.5 \%$ of the indicators. It is necessary to expand the international participation of these programs and to strengthen networks between Brazil and foreign countries.

\section{INTRODUÇÃO}

A internacionalização é um tema bastante difundido dentro das empresas, sendo que diversas teorias como da internacionalização de empresas, internacionalização de PMEs, teoria de redes e demais, vêm, ao longo dos anos, embasando essa ação, que pode contribuir ricamente para o desenvolvimento das empresas, diante da atual e forte concorrência oriunda de diversas partes do mundo (CHILD E RODRIGUES, 2005).

Quando se fala sobre internacionalização, a principal referência é a aplicação de uma estratégia por parte de empresas, principalmente das manufaturas, visando ao crescimento, à expansão e objetivando ao final o aumento do lucro e da participação no mercado. 
Entretanto, trata-se de uma teoria que pode ser aplicada em outros campos que não necessariamente visam ao lucro imediato, mas que buscam fazer parte de um contexto internacional afim de agregar os benefícios advindos de um cenário globalizado (CHILD E RODRIGUES, 2005).

A internacionalização aplicada ao ensino também é uma forma de as universidades ou, mais especificamente, os seus programas de pós-graduação - agregarem valor no seu campo de atuação. Isto é, através da internacionalização do ensino, a formação de redes pode ser uma estratégia para os programas de pós-graduação das universidades se diferenciarem de outros. A troca de experiências e a aquisição de conhecimentos e de informações são benefícios que podem ser mais bem alcançados por meio da internacionalização, uma vez que há formação de redes entre os pesquisadores e ou entre os professores pertencentes aos programas. Por meio dessa interação, as universidades podem obter vantagens competitivas em relação àquelas que não o praticam.

A presente pesquisa enfoca a internacionalização dos programas de pós-graduação stricto sensu em Administração com avaliação 6 e 7 pela CAPES, e visa a responder à seguinte pergunta orientadora: qual o fator de relevância do grau de internacionalização dos programas de pós- graduação na sua avaliação de desempenho, de acordo com a CAPES?

Para atingir o objetivo geral de verificar em que medida o grau de internacionalização dos programas de pós-graduação reflete em seu desempenho geral, estabeleceram-se os seguintes objetivos específicos: a) verificar a formação dos docentes vinculados aos programas e sua relação com publicações no exterior; b) analisar o cumprimento de cada um dos indicadores de internacionalização propostos pela CAPES; e c) identificar as redes de interação internacional dos programas selecionados no Brasil.

A pós-graduação é um mecanismo organizacional por meio do qual se produz conhecimento, sendo a utilização das redes uma das estratégicas para ampliar esse conhecimento, principalmente devido à velocidade e pressão organizacionais. Stallivieri (2008) afirma que as redes de cooperação formadas pelas universidades aproximam as comunidades científicas de diferentes partes do planeta. Isso reforça a premissa de que é no seio da universidade que devem ocorrer os grandes avanços científicos e tecnológicos e a efetiva integração dos povos, respeitando, acima de tudo, as diferenças e as especificidades de cada nação.

Este tema apresenta relevância acadêmica, uma vez que fornece informações sobre a produção científica das universidades brasileiras, em particular a forma como estão cumprindo as diretrizes dos indicadores solicitados para os programas de pós-graduação em Administração com conceitos 6 e 7 pela CAPES, únicos por ela considerados com elevado grau de internacionalização. A presente pesquisa busca contribuir para o planejamento de outros programas de pós-graduação, fornecendo informações para auxiliá-los em seu planejamento, visando possivelmente à busca ou ao crescimento da internacionalização.

Para a CAPES, a presente pesquisa fornece informações de como essa rede de cooperação é trabalhada na prática entre as universidades pesquisadas, e se os programas classificados com maior desempenho, segundo seu sistema de avaliação, realmente demonstram maior nível de internacionalização. Para o Brasil, contribui conferindo-lhe 
maior visibilidade em relação à maneira e aos locais onde está ocorrendo a formação de redes de cooperação internacional.

\section{TEORIA DE REDES}

Grandori e Soda (1995) definem redes como formas de organização da atividade econômica que funcionam por meio de ações de coordenação e cooperação interorganizacionais. Essas relações, do ponto de vista econômico, baseiam-se em contratos formais ou informais firmados na estruturação da rede e na entrada de um novo integrante. Segundo os autores, as redes são formadas por estrutura celular não rigorosa, e compostas de atividades de valor agregado, que constantemente introduzem novos materiais e elementos.

Em uma análise mais incisiva, Castells (1999) afirma que as redes constituem um conjunto de nós interconectados, sendo que um nó depende do tipo de redes concretas no qual ele está inserido. Alves (2008) acrescenta ainda que são formas de, numa atividade em conjunto, organizar os relacionamentos entre os atores, privilegiando a cooperação mútua e a flexibilização da estrutura funcional. Essa interação, todavia, não elimina a competição e os conflitos de ideias.

Segundo Ribeiro et al. (2013), para analisar uma rede, é necessária a compreensão da sua estrutura, assim como das relações que a compõem. A principal propriedade estrutural da rede é sua densidade, que pode ser entendida através da extensão da interconexão entre os atores - ou seja, quanto maior a interconexão, maior a densidade. Tratando-se das relações entre os atores, a coesão entre eles é o indicador mais representativo da densidade. A centralidade, a densidade e a transitividade - essa última significando a probabilidade de duas pessoas estarem conectadas - são algumas das principais propriedades estruturais de uma rede (RIBEIRO et al., 2013). A centralidade divide-se em centralidade de grau, de proximidade e de intermediação. A centralidade de grau (em inglês, degree) é definida pela atividade relacional direta de um ator; nesse sentido, segundo Ribeiro et al. (2013), o ator que ocupa uma posição mais central é aquele que possui o maior número de conexões. A centralidade de proximidade (em inglês, closeness) é a função da proximidade ou da distância de um ator em relação a todos os outros numa rede. A ideia percebida na análise desse indicador é a de que um ator com elevada centralidade de aproximação é aquele que possui maiores condições de interagir rapidamente com todos os outros.

Por fim, a centralidade de intermediação (em inglês, betweenness) avalia a dependência de atores não adjacentes a outros que atuam como uma espécie de ponte para a efetivação da interação entre eles. Nesse caso, quanto mais próximo um ator se encontrar de uma posição intermediária - ou seja, os atores tiverem que passar por ele para chegar aos outros - maior a capacidade desse de controlar as relações dentro da rede.

De acordo com Freire et al. (2010), estruturalmente as redes podem ser densas ou difusas, conforme a posição de um ator na estrutura da rede e seus efeitos na posição de atuação. Isso significa dizer, segundo os autores, que, quanto mais central a posição de um 
ator na rede, mais relações serão estabelecidas com outros atores, direta ou indiretamente, por relações em cadeia, tornando a rede mais densa. Freire et al. (2010) reforçam o conceito de densidade da rede, que aumenta à medida que a inter-relação entre seus atores cresce. Além disso, pode haver uma variação do posicionamento estrutural de um ator conforme a densidade da rede. A confiança inerente às redes densas permite um maior fluxo de informação; já as redes difusas são menos interconectadas, no entanto não admitem redundância em suas relações, facilitando o acesso a novas informações.

Para Ribeiro et al. (2013), as redes de conhecimento, assim como a maioria das redes sociais, têm, na coesão, um dos seus principais elementos de análise. Assim, no comportamento coletivo dos atores de um mesmo grupo, a coesão serve de base para a solidariedade e identidade do grupo. Esses autores concordam com Freire et al. (2010) e complementam que, estruturalmente, além de poderem ser densas ou difusas, as redes podem ter conexões fortes ou fracas. Conexões fracas e redes difusas são mais comuns em ambientes instáveis, pois permitem maior fluxo de novas informações. Por seu turno, conexões fortes e redes densas são mais frequentes em ambientes estáveis, já que a troca de informações é refinada e há um alto nível de confiança, de cooperação, de reciprocidade e de controle social entre os atores. Entretanto, uma situação de conexão forte e de rede densa pode conduzir ao isolamento do grupo e a uma possível dificuldade de acesso desses atores a novas informações que circulem fora daquele ambiente restrito (RIBEIRO et al., 2013).

O conceito de laços fortes e fracos é um ponto destacado por Freire et al. (2010) e por Lemieux e Ouimet (2012) na teoria embasada por Granovetter (1973), que afirma que os laços fortes são aqueles que unem os atores por apresentarem maior proximidade e frequência. Já os laços fracos são caracterizados por uma relação mais distante, em que a interação entre os atores é menor. Lemieux e Ouimet (2012) destacam que laços fortes tornam as redes mais fortes; já os laços fracos possibilitam mais maleabilidade às redes, podendo conferir-Ihes estruturas diferentes.

Freire et al. (2010) apontam que os laços fracos exercem o papel de aglutinador em redes densas além de estabelecerem comunicação e troca de informações entre essas. Os autores ressaltam 'a força dos laços fracos', já que, por não serem estruturas fechadas, permitem aos atores obter informações novas fora do grupo de relações fortemente conectadas, nas redes densas. Nesse sentido, Limieux e Ouimet (2012) reforçam que as redes dos laços fortes possuem, por conseguinte, muito mais tendência para se fechar sobre si mesmas que as redes de laços fracos, que tendem normalmente a abrir-se para o exterior. Os autores corroboram a teoria de Burt (1992) de que os buracos estruturais não existem nos grupos constituídos por laços fracos, sendo numerosos nos grupos de fraca densidade, em que se verifica a ausência de conexões diretas em vários pares de autores.

Burt (1992) aponta que a força do laço é a forma como a arquitetura da rede interfere no desempenho, visando a entender como a estrutura social do ambiente competitivo gera oportunidades para obter benefícios de informação e controle. Também destaca que a arquitetura da rede interfere em seu desempenho. Ao propor os conceitos de relação redundante e não redundante, o autor apresenta a existência de buracos estruturais, 
como relações de não redundância entre atores. Sua conclusão é de que os laços fracos são fundamentais para a transmissão de novas informações, desde que não sejam redundantes, dado que a redundância afeta a capacidade de inovação.

Miranda et al. (2013) consideram, como pressuposto, que um membro do corpo docente que publica é muito mais valioso para a comunidade educativa do que aquele que não publica. Em complemento a essa ideia, Hudson (1996) acrescenta que a produção de estudos em parceria proporciona resultado qualitativamente superior àqueles desenvolvidos isoladamente, ressaltando que a principal vantagem da coautoria - isto é, o envolvimento de dois ou mais pesquisadores nessa produção - é a divisão do trabalho e a possibilidade da integração de pesquisadores com diferentes habilidades. Stallivieri (2008) acrescenta que as redes de cooperação formadas pelas universidades aproximam as comunidades cientificas em diferentes países, fortalecendo a imagem de que é na universidade onde devem ocorrer os grandes avanços científicos e tecnológicos e a efetiva integração dos povos, sobretudo respeitando as diferenças e especificidades de cada nação.

Segundo Alves et al. (2010), frente ao aumento da globalização, as empresas buscam formas de elevar a competitividade, sendo uma delas o estabelecimento de relações em redes de cooperação. Essas relações possibilitam a troca de conhecimento, o compartilhamento de informações, e uma melhor adaptação às mudanças e inovações, que colaboram para a sobrevivência das pequenas e médias empresas. Para Castells (1999), novas oportunidades são criadas o tempo todo quando se está dentro das redes, mas fora delas a sobrevivência ficará cada vez mais difícil. O autor ressalta a importância da transformação tecnológica que estabelece a integração em redes como forma fundamental de concorrência na nova economia global. Também destaca a elevação das barreiras que impedem o acesso de novas organizações isoladas em setores mais avançados da economia, dificultado a entrada de novos concorrentes. Nesse contexto, a cooperação e os sistemas de redes seriam a única forma de minimizar os riscos, dividir os custos e manter-se em dia com a informação constantemente atualizada.

\section{TEORIA DA INTERNACIONALIZAÇÃO DE ENSINO SUPERIOR}

As palavras 'internacional' e 'internacionalização' são frequentemente empregadas hoje em dia no contexto acadêmico, em parte devido ao aumento do número de estudantes oriundos de outros países. Nesse sentido, é cada vez mais comum e mais politicamente correto o emprego de 'internacional' em vez de 'estrangeiro'. O termo também é aplicado em relação à importância atribuída à reputação internacional de uma instituição como uma medida de excelência, e em relação ao impacto da globalização e da emergência do 'cidadão internacional' ou 'cidadão global' (HARRIS, 2008).

De acordo com De Wit (1998), as expressões 'globalização do ensino superior' e 'educação internacional' não devem ser usadas como sinônimos de internacionalização. A primeira não distingue a relação de causa e efeito entre os processos de internacionalização e globalização. Já a segunda transmite a ideia de que a educação superior encontra-se num estágio de completa internacionalização. 
Bennett e Kottasz (2011) definem internacionalização do ensino como o processo de integração de uma dimensão internacional, intercultural e global, com a função de ofertar ensino. Para os autores, a internacionalização envolve uma infinidade de tarefas, tais como organização, financiamento e decisões estratégicas como, por exemplo, a franquia internacional, o currículo, colaborações de pesquisa, joint ventures transfronteiriços, a criação de campi em outros países e de programas de intercâmbio entre professores e entre estudantes, bem como o recrutamento de professores com competência e experiência internacionais. Laus e Morosini (2005 apud DE WIT et al., 1997, p. 2) definem a internacionalização da educação como "o processo de integração de uma dimensão internacional/intercultural para as funções das instituições de ensino, pesquisa e serviços". Maas-Garcia e Ter Maten-Speksnijder (2009) afirmam que o conceito de internacionalização na educação é baseado em justificativas econômicas, assim listadas por De Wit (2002): a) ênfase na internacionalização, devido às exigências do mercado de trabalho moderno, mais global; b) projetos internacionais de pesquisa e de desenvolvimento internacionais para competir globalmente em nova tecnologia; c) atenção para a comercialização do ensino superior no mercado internacional; e d) ensino superior como produto de exportação. Harris (2008) também defende o argumento de que a internacionalização é importante para a captação de recursos para as universidades, pois essas podem aumentar consideravelmente seus rendimentos através de taxas cobradas dos alunos estrangeiros.

A mobilidade de estudantes, de professores e de gestores intensifica, com muita voracidade, os laços transnacionais, estabelecendo conexões e criando redes de saber universal. Essas redes aproximam as comunidades científicas de diferentes partes do planeta, reforçando a premissa de que é no seio da universidade que devem ocorrer os grandes avanços científicos e tecnológicos e a efetiva integração. (STALLIVIERI, 2008, p. 17)

Bennet e Kottasz (2011) apontam duas linhas de internacionalização de universidades. A primeira é de abordagem cooperativa, isto é, a cooperação se manifesta em redes acadêmicas por meio de acordos estratégicos de cooperação e de alianças institucionais que permitam aos parceiros: a) se especializarem em determinadas linhas de trabalho; b) terem acesso a ativos de propriedade um do outro (por exemplo, acesso online à biblioteca de uma instituição parceira); e c) aprenderem sobre novas abordagens e inovações educacionais no país do outro parceiro.

Alianças institucionais permitem uma rápida entrada nos mercados estrangeiros e a aquisição de conhecimento em novos métodos pedagógicos e em pesquisa desenvolvidos em outros lugares, por exemplo, através do uso de currículos e de programas de ensino do parceiro (BENNETT; KOTTASZ, 2011)

A segunda abordagem da internacionalização seria pela competitividade, principalmente após o acirramento da concorrência no mercado da educação, a partir dos anos de 1990. Bennett e Kottasz (2011) destacam que as manifestações de uma abordagem competitiva poderiam incluir: a busca constante de nichos de mercado nos países em desenvolvimento; a implementação de modos especiais e mais flexíveis de estudo para estudantes estrangeiros; a criação de novas unidades em países estrangeiros, sem o envolvimento de parceiros locais; a concessão de incentivos para premiar funcionários que 
implementem, com sucesso, operações estrangeiras; corte de preço (das taxas de estudante que algumas universidades cobram dos alunos); a contratação de agentes de recrutamento estrangeiros para realizar marketing agressivo e forte publicidade em outros países; e, por fim, a alavancagem promocional de reputação superior de uma instituição em mercados de moeda estrangeira.

Uma das motivações para a formação de redes internacionais é o acesso a recursos financeiros, já que houve redução de recursos disponibilizados pelos governos de forma geral, depois dos anos de 1990, e existe a possibilidade de obtenção de recursos externos, além do fortalecimento da marca e do nome da universidade.

Horta (2009) salienta que as universidades que se estabelecem com ensino superior global: têm vantagem competitiva frente às outras; normalmente pertencem a países com sistemas científicos dominantes; e têm mais recursos ou melhor reputação, bem como mais experiência, por meio do desenvolvimento de atividades ao nível internacional. A internacionalização do ensino imprime a elas uma marca, fazendo com que sejam reconhecidas internacionalmente por sua qualidade de ensino e de pesquisa.

Essas repercussões reforçam ainda mais a ideia de que a internacionalização do ensino pode ser vantajosa e elevar a competitividade das universidades, a exemplo do ocorrido com as instituições europeias de ensino superior, que têm fortes nomes reconhecidos em todo o mundo. Stallivieri (2008) destaca pontos que podem ser considerados obstáculos à internacionalização a serem observados pelas universidades ao delimitarem sua área de atuação: restrições em termos de localização geográfica das universidades parceiras, existência de barreiras linguísticas, áreas de excelência do conhecimento no ensino ou na pesquisa, e, ainda, o nível de desenvolvimento do país onde está localizada a instituição.

Miura (2006) complementa que a educação de ensino superior precisa preparar os estudantes para viver e trabalhar em um mundo cada vez mais conectado e interdependente de informações. Ao mesmo tempo, deve atentar para a importância da pesquisa em termos de contribuição para o desenvolvimento de questões de interesses nacionais e internacionais. Para a autora, os obstáculos à internacionalização são os aspectos organizacionais das universidades, são "deficiências ou carências em política ou plano estratégico, escritórios de relações internacionais, orçamento, estrutura de monitoramento das atividades, corpo administrativo para atender às demandas da internacionalização entre outros" (MIURA, 2006, p. 256).

\section{ASPECTOS DO MÉTODO}

Nesta pesquisa, utilizam-se as abordagens qualitativa e quantitativa, método que se desenvolveu em resposta à necessidade de reunir dados quantitativos e evidências qualitativas em um único estudo (CRESWELL, 2007). Para se alcançar o objetivo proposto nessa pesquisa - analisar o desempenho dos indicadores de internacionalização dos programas de pós-graduação em Administração considerados pela CAPES - foi consultada a última avaliação disponibilizada pela instituição em 2013 referente ao triênio 2010-12. Os 
dados utilizados para o desenvolvimento desta pesquisa são secundários, ou seja, "aqueles que já foram coletados, tabulados, ordenados e, às vezes, até analisados e que estão catalogados à disposição dos interessados" (MATTAR, 2000, p. 134).

No website da CAPES, foram selecionados os programas de Administração que obtiveram notas 6 ou 7 no triênio 2010-12 - únicas consideradas pela CAPES para aqueles com elevado grau de internacionalização. Em seguida, no item 'Cadernos de Indicadores' foram analisados os comentários da CAPES nas respectivas Fichas de Avaliação a respeito dos professores visitantes, do intercâmbio de alunos nacionais e estrangeiros, dos projetos e das linhas de pesquisas, da produção e da atuação docente, Outras informações mais detalhadas, tais como a formação dos professores participantes dos programas em questão (instituição, ano de formação, orientador, se sanduíche ou não), habilidades com outros idiomas e ser membro e ou revisor de corpo editorial, foram coletadas no sistema Lattes de currículos (CNPQ, 2014).

Todas as informações foram estruturadas em um banco de dados para posteriormente possibilitar a análise do desempenho dos indicadores de internacionalização dos programas selecionados. O programa scriptlattes foi utilizado para auxiliar na consolidação das informações disponibilizadas pelos pesquisadores em seus currículos, bem como visualizar de forma objetiva as informações sobre publicações, produções, orientações, projetos de pesquisas e participação em eventos por cada instituição e nos anos do triênio estudado. Posteriormente foi feita análise de conteúdo das informações obtidas.

\section{ANÁLISE DE DADOS}

\subsection{Formação}

De acordo com os dados coletados no 'Caderno de Docente Atuação' disponível no site da CAPES, verificou-se a existência de 123 professores - dos quais sendo 25 na Fundação Getulio Vargas do Rio de Janeiro (FGV-RJ), 33 na Fundação Getulio Vargas de São Paulo (FGV-SP), 22 na Universidade Federal de Minas Gerais (UFMG) e 43 na Universidade de São Paulo (USP) - vinculados aos programas stricto sensu das universidades pesquisadas. Em seguida, obtiveram-se os nomes para posterior busca dos respectivos currículos Lattes e para a análise sobre sua formação, sendo que todos os docentes apresentaram doutorado (ver Tabela 1). Em relação à distribuição dos docentes com pós-doutorado, observa-se que $42 \%$ são da FGV-SP, $40 \%$ são da USP, $36 \%$ são da UFMG e $28 \%$ são da FGV-RJ. O tempo médio de formação foi significativamente diferente entre pelo menos duas instituições em todos os níveis de instrução.

Tabela 1 - Número de docentes em cada nível de instrução por instituição e tempo médio de formação entre as instituições por nível de instrução (2010-2012)

\begin{tabular}{c|l|c|c|c|c}
\hline Nível & Instituição & $\begin{array}{c}\text { No de } \\
\text { docentes }\end{array}$ & $\begin{array}{c}\text { \% dos } \\
\text { docentes que } \\
\text { contem o } \\
\text { título }\end{array}$ & $\begin{array}{c}\text { Média de } \\
\text { docentes no } \\
\text { nível }\end{array}$ & Valor-p \\
\hline Mestrado & FGV-RJ & 25 & $100 \%$ & 21,8 & 0,033 \\
\hline
\end{tabular}




\begin{tabular}{|c|c|c|c|c|c|}
\hline Nível & Instituição & $\begin{array}{c}\text { № de } \\
\text { docentes }\end{array}$ & $\begin{array}{c}\% \text { dos } \\
\text { docentes que } \\
\text { contem o } \\
\text { título }\end{array}$ & $\begin{array}{c}\text { Média de } \\
\text { docentes no } \\
\text { nível }\end{array}$ & Valor-p \\
\hline & FGV-SP & 31 & $94 \%$ & 23,4 & \\
\hline & UFMG & 22 & $100 \%$ & 21,1 & \\
\hline & USP & 40 & $93 \%$ & 27,8 & \\
\hline \multirow{4}{*}{ Doutorado } & FGV-RJ & 25 & $100 \%$ & 14,3 & \multirow{4}{*}{0} \\
\hline & FGV-SP & 33 & $100 \%$ & 16,1 & \\
\hline & UFMG & 22 & $100 \%$ & 14,5 & \\
\hline & USP & 43 & $100 \%$ & 22,8 & \\
\hline \multirow{4}{*}{ Pós- Doutorado } & FGV-RJ & 7 & $28 \%$ & 7,6 & \multirow{4}{*}{0,015} \\
\hline & FGV-SP & 14 & $42 \%$ & 7 & \\
\hline & UFMG & 8 & $36 \%$ & 7,6 & \\
\hline & USP & 17 & $40 \%$ & 19,6 & \\
\hline
\end{tabular}

Fonte: Elaboração própria com base no currículo Lattes (CNPQ, 2014).

Tabela 2 - Contingência e teste de Qui-Quadrado entre o local de formação e as instituições em cada nível de instrução - Triênio 2010-12

\begin{tabular}{|c|c|c|c|c|c|c|c|c|}
\hline \multirow{2}{*}{ Nível } & \multirow{2}{*}{ Instituição } & \multicolumn{6}{|c|}{ Local de Formação } & \multirow{2}{*}{ Valor-p } \\
\hline & & \multicolumn{2}{|c|}{ Exterior } & \multicolumn{2}{|c|}{ Brasil } & \multicolumn{2}{|c|}{ Total } & \\
\hline \multirow{5}{*}{ Mestrado } & FGV-RJ & 7 & $28,0 \%$ & 18 & $72,0 \%$ & 25 & $100,0 \%$ & \multirow{5}{*}{0,079} \\
\hline & FGV-SP & 7 & $23,3 \%$ & 23 & $76,7 \%$ & 30 & $100,0 \%$ & \\
\hline & UFMG & 1 & $4,8 \%$ & 20 & $95,2 \%$ & 21 & $100,0 \%$ & \\
\hline & USP & 4 & $10,0 \%$ & 36 & $90,0 \%$ & 40 & $100,0 \%$ & \\
\hline & Total & 19 & $16,4 \%$ & 97 & $83,6 \%$ & 116 & $100,0 \%$ & \\
\hline \multirow{5}{*}{ Doutorado } & FGV-RJ & 11 & $44,0 \%$ & 14 & $56,0 \%$ & 25 & $100,0 \%$ & \multirow{5}{*}{0,001} \\
\hline & FGV-SP & 9 & $27,3 \%$ & 24 & $72,7 \%$ & 33 & $100,0 \%$ & \\
\hline & UFMG & 9 & $40,9 \%$ & 13 & $59,1 \%$ & 22 & $100,0 \%$ & \\
\hline & USP & 2 & $4,8 \%$ & 40 & $95,2 \%$ & 42 & $100,0 \%$ & \\
\hline & Total & 31 & $25,4 \%$ & 91 & $74,6 \%$ & 122 & $100,0 \%$ & \\
\hline \multirow{5}{*}{$\begin{array}{c}\text { Pós- } \\
\text { Doutorado }\end{array}$} & FGV-RJ & 7 & $100,0 \%$ & 0 & $0,0 \%$ & 7 & $100,0 \%$ & \multirow{5}{*}{0,128} \\
\hline & FGV-SP & 8 & $57,1 \%$ & 6 & $42,9 \%$ & 14 & $100,0 \%$ & \\
\hline & UFMG & 5 & $62,5 \%$ & 3 & $37,5 \%$ & 8 & $100,0 \%$ & \\
\hline & USP & 14 & $82,4 \%$ & 3 & $17,6 \%$ & 17 & $100,0 \%$ & \\
\hline & Total & 34 & $73,9 \%$ & 12 & $26,1 \%$ & 46 & $100,0 \%$ & \\
\hline
\end{tabular}

Fonte: Elaboração própria com base no currículo Lattes (CNPQ, 2014).

A Tabela 2 apresenta a comparação entre as instituições no que se refere ao número de mestrado, doutorado e pós-doutorado realizados no exterior. Pode-se verificar que, para o nível doutorado, houve diferença significativa (Valor-p $=0,001$ ) entre FGV-RJ, FGV-SP, 
UFMG e USP, que apresentaram, respectivamente, 44\%, 27,27\%, 40,91\% e 4,76\% de docentes estudando no exterior. No caso, a USP difere de todas as outras instituições por ter menor percentual de docentes com doutorado no exterior. Os outros níveis de instrução não apresentaram diferenças significativas entre as instituições.

Analisando a formação dos docentes tanto no que diz respeito ao tempo quanto na questão do local (Brasil ou exterior), é preciso destacar que a USP apresenta o menor número de docentes com doutorado cursado no exterior, embora ela tenha apresentado a maior média de tempo de formação de seus doutores. Em outras palavras, a USP apresentou a maior média de doutores seniores, mas formados no Brasil e não no exterior. A mobilidade dos docentes é ressaltada por Stallivieri (2008) como importante para fortalecer os laços transnacionais e estabelecer conexões, criando redes de saber universal.

O Gráfico 1 detalha quais países em que os docentes tiveram formação ou parte dela no exterior - ou seja, os países de maior relacionamento. No caso, os quatro programas selecionados apresentam maior aderência com os Estados Unidos e a Inglaterra, nessa ordem, sendo perceptível a forte relação da formação dos docentes com países de língua inglesa.

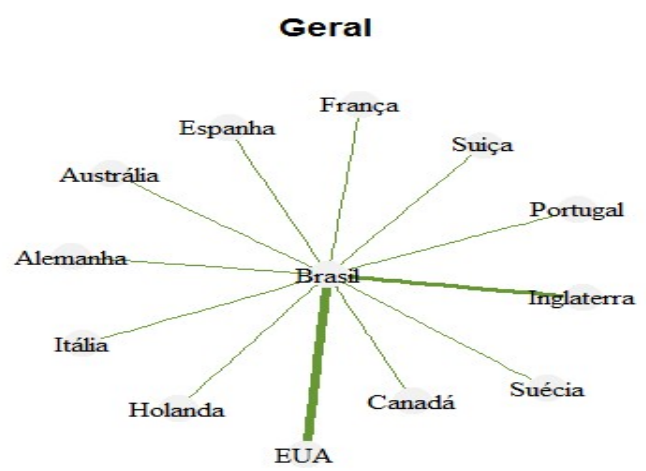

Gráfico 1 - Rede geral deformação internacional dos docentes dos quatro programas selecionados Triênio 2010-12

Fonte: Elaboração própria com base em dados do currículo Lattes(CNPQ, 2014).

Se utilizado como ferramenta para auxiliar e ampliar a comunicação, bem como para propiciar a interação entre os docentes e discentes, o idioma é importante para a verificação do nível declarado de comunicação dos docentes das instituições pesquisadas quanto à leitura, à compreensão, à fala e à escrita. Por esse motivo, foi investigado quais são os idiomas declarados pelos docentes como utilizados por eles, dentro do critério disponibilizados pelo Lattes.

Como resultado encontrou-se que o inglês é o idioma mais utilizado com 120 do total de docentes informando que lê, compreende, fala e escreve nessa língua. Em seguida vêm o espanhol, com 101 docentes, e o francês, com 71 docentes. Todos os docentes da FGV-RJ e da FGV-SP informaram utilizar o inglês, enquanto respectivamente 21 e 41 docentes da UFMG e da USP se comunicam nesse idioma. A USP foi à instituição com o maior número de docentes que utiliza o francês, a UFMG aquela que mais utiliza o espanhol, e a FGV-SP a que mais utiliza o italiano e o alemão. 


\subsection{Publicação}

Miranda et al. (2013) consideram, como pressuposto, que um membro do corpo docente que publica é muito mais valioso para a comunidade educativa do que aquele que não publica. Por isso, há crescente preocupação com o número de publicações. Além disso não basta publicar; o importante é fazê-lo em parceria, para elevar a qualidade da produção e integrar pesquisadores que tenham diferentes habilidades - daí a importância em publicar com pesquisadores de outras instituições em outros países (HUDSON, 1996; STALLIVIERI, 2008; ALVES et al. (2010). Silva (2002) complementa que esse tipo de trabalho proporciona economia de tempo e de recursos, considerando que, frente a essa necessidade de elevado número de publicações com qualidade, a rede de coautoria, apontada por Acedo et al. (2006), por Hudson (1996) e por Banett et al. (1988), é uma forma de alcançar este objetivo.

Na Tabela 3 é possível verificar o número e o percentual de publicações no Brasil e no exterior de cada um dos programas das quatro instituições pesquisadas no triênio 2010-12.

Tabela 3 - Contingência e teste de Qui-Quadrado entre as instituições pesquisadas e o local de publicação por ano - Triênio 2010-12

\begin{tabular}{|c|c|c|c|c|c|c|c|c|}
\hline \multirow{3}{*}{ Ano } & \multirow{3}{*}{ Instituição } & \multicolumn{6}{|c|}{ Publicação } & \multirow{3}{*}{ Valor-p } \\
\hline & & \multicolumn{2}{|c|}{ Brasil } & \multicolumn{2}{|c|}{ Exterior } & \multicolumn{2}{|c|}{ Total } & \\
\hline & & № & $\%$ & № & $\%$ & № & $\%$ & \\
\hline \multirow{5}{*}{2010} & FGV RJ & 37 & $57,8 \%$ & 27 & $42,2 \%$ & 64 & $100,0 \%$ & \multirow{5}{*}{0,000} \\
\hline & FGV SP & 53 & $72,6 \%$ & 20 & $27,4 \%$ & 73 & $100,0 \%$ & \\
\hline & UFMG & 83 & $92,2 \%$ & 7 & $7,8 \%$ & 90 & $100,0 \%$ & \\
\hline & USP & 96 & $81,4 \%$ & 22 & $18,6 \%$ & 118 & $100,0 \%$ & \\
\hline & Total & 269 & $78,0 \%$ & 76 & $22,0 \%$ & 345 & $100,0 \%$ & \\
\hline \multirow{5}{*}{2011} & FGV RJ & 39 & $60,9 \%$ & 25 & $39,1 \%$ & 64 & $100,0 \%$ & \multirow{5}{*}{0,000} \\
\hline & FGV SP & 71 & $75,5 \%$ & 23 & $24,5 \%$ & 94 & $100,0 \%$ & \\
\hline & UFMG & 78 & $90,7 \%$ & 8 & $9,3 \%$ & 86 & $100,0 \%$ & \\
\hline & USP & 87 & $81,3 \%$ & 20 & $18,7 \%$ & 107 & $100,0 \%$ & \\
\hline & Total & 275 & $78,3 \%$ & 76 & $21,7 \%$ & 351 & $100,0 \%$ & \\
\hline \multirow{5}{*}{2012} & FGV RJ & 31 & $62,0 \%$ & 19 & $38,0 \%$ & 50 & $100,0 \%$ & \multirow{5}{*}{0,001} \\
\hline & FGV SP & 54 & $65,1 \%$ & 29 & $34,9 \%$ & 83 & $100,0 \%$ & \\
\hline & UFMG & 85 & $87,6 \%$ & 12 & $12,4 \%$ & 97 & $100,0 \%$ & \\
\hline & USP & 104 & $73,8 \%$ & 37 & $26,2 \%$ & 141 & $100,0 \%$ & \\
\hline & Total & 274 & $73,9 \%$ & 97 & $26,1 \%$ & 371 & $100,0 \%$ & \\
\hline
\end{tabular}

Fonte: Elaboração própria a partir do scriptLattes (MENA-CHALCO; CESAR Jr., 2009).

Observa-se que, em cada um dos anos pesquisados, houve diferença significativa entre as instituições no percentual de artigos publicados no exterior. Em todos os anos, a ordem decrescente de publicação no exterior foi FGV-RJ, FGV-SP, USP e UFMG. O valor-p reforça estatisticamente que não houve diferença significativa entre um programa e outro. 
A Tabela 4 detalha quais foram os países onde publicaram os programas vinculados às instituições pesquisadas e o percentual de publicações no exterior de cada um dos programas selecionados, ao longo do triênio 2010-12. O maior destaque fica para os Estados Unidos e Inglaterra, que ocupam respectivamente o primeiro e o segundo lugares. Com isso, reforça-se a ideia de que os docentes tendem a publicar em países cujo idioma eles dominam.

Tabela 4 - Países que receberam publicação referente aos programas selecionados, o número de ocorrência e o percentual- (Triênio 2010-12)

\begin{tabular}{|c|c|c|c|c|c|c|c|c|c|c|}
\hline \multirow{2}{*}{ País } & \multicolumn{2}{|c|}{ GERAL } & \multicolumn{2}{|c|}{ FGV-RJ } & \multicolumn{2}{|c|}{ FGV-SP } & \multicolumn{2}{|c|}{ UFMG } & \multicolumn{2}{|c|}{ USP } \\
\hline & № & $\%$ & № & $\%$ & № & $\%$ & № & $\%$ & № & $\%$ \\
\hline EUA & 91 & $36,5 \%$ & 40 & $56 \%$ & 25 & $35 \%$ & 6 & $22 \%$ & 20 & $25 \%$ \\
\hline Inglaterra & 48 & $19,3 \%$ & 11 & $15 \%$ & 18 & $25 \%$ & 4 & $15 \%$ & 15 & $19 \%$ \\
\hline Venezuela & 22 & $8,8 \%$ & 0 & $0 \%$ & 5 & $7 \%$ & 0 & $0 \%$ & 17 & $22 \%$ \\
\hline Espanha & 11 & $4,4 \%$ & 1 & $1 \%$ & 4 & $6 \%$ & 2 & $7 \%$ & 4 & $5 \%$ \\
\hline Ucrânia & 9 & $3,6 \%$ & 1 & $1 \%$ & 2 & $3 \%$ & 6 & $22 \%$ & 0 & $0 \%$ \\
\hline Argentina & 8 & $3,2 \%$ & 2 & $3 \%$ & 1 & $1 \%$ & 2 & $7 \%$ & 3 & $4 \%$ \\
\hline Chile & 8 & $3,2 \%$ & 0 & $0 \%$ & 4 & $6 \%$ & 1 & $4 \%$ & 3 & $4 \%$ \\
\hline Canadá & 7 & $2,8 \%$ & 2 & $3 \%$ & 4 & $6 \%$ & 1 & $4 \%$ & 0 & $0 \%$ \\
\hline China & 6 & $2,4 \%$ & 4 & $6 \%$ & 0 & $0 \%$ & 1 & $4 \%$ & 1 & $1 \%$ \\
\hline África do Sul & 5 & $2,0 \%$ & 1 & $1 \%$ & 2 & $3 \%$ & 1 & $4 \%$ & 1 & $1 \%$ \\
\hline Índia & 4 & $1,6 \%$ & 0 & $0 \%$ & 3 & $4 \%$ & 0 & $0 \%$ & 1 & $1 \%$ \\
\hline Suíça & 4 & $1,6 \%$ & 1 & $1 \%$ & 2 & $3 \%$ & 1 & $4 \%$ & 0 & $0 \%$ \\
\hline Alemanha & 3 & $1,2 \%$ & 1 & $1 \%$ & 0 & $0 \%$ & 0 & $0 \%$ & 2 & $3 \%$ \\
\hline França & 3 & $1,2 \%$ & 3 & $4 \%$ & 0 & $0 \%$ & 0 & $0 \%$ & 0 & $0 \%$ \\
\hline México & 3 & $1,2 \%$ & 1 & $1 \%$ & 0 & $0 \%$ & 0 & $0 \%$ & 2 & $3 \%$ \\
\hline Colômbia & 2 & $0,8 \%$ & 0 & $0 \%$ & 0 & $0 \%$ & 0 & $0 \%$ & 2 & $3 \%$ \\
\hline Holanda & 2 & $0,8 \%$ & 0 & $0 \%$ & 2 & $3 \%$ & 0 & $0 \%$ & 0 & $0 \%$ \\
\hline Itália & 2 & $0,8 \%$ & 0 & $0 \%$ & 0 & $0 \%$ & 1 & $4 \%$ & 1 & $1 \%$ \\
\hline Singapura & 2 & $0,8 \%$ & 0 & $0 \%$ & 0 & $0 \%$ & 0 & $0 \%$ & 2 & $3 \%$ \\
\hline Taiwan & 2 & $0,8 \%$ & 2 & $3 \%$ & 0 & $0 \%$ & 0 & $0 \%$ & 0 & $0 \%$ \\
\hline Austrália & 1 & $0,4 \%$ & 0 & $0 \%$ & 0 & $0 \%$ & 0 & $0 \%$ & 1 & $1 \%$ \\
\hline Catalunha & 1 & $0,4 \%$ & 1 & $1 \%$ & 0 & $0 \%$ & 0 & $0 \%$ & 0 & $0 \%$ \\
\hline Coreia do Sul & 1 & $0,4 \%$ & 0 & $0 \%$ & 0 & $0 \%$ & 0 & $0 \%$ & 1 & $1 \%$ \\
\hline Eslovênia & 1 & $0,4 \%$ & 0 & $0 \%$ & 0 & $0 \%$ & 1 & $4 \%$ & 0 & $0 \%$ \\
\hline Israel & 1 & $0,4 \%$ & 0 & $0 \%$ & 0 & $0 \%$ & 0 & $0 \%$ & 1 & $1 \%$ \\
\hline Porto Rico & 1 & $0,4 \%$ & 0 & $0 \%$ & 0 & $0 \%$ & 0 & $0 \%$ & 1 & $1 \%$ \\
\hline Romênia & 1 & $0,4 \%$ & 0 & $0 \%$ & 0 & $0 \%$ & 0 & $0 \%$ & 1 & $1 \%$ \\
\hline
\end{tabular}

Fonte: Elaboração própria a partir do scriptLattes (MENA-CHALCO; CESAR Jr., 2009). 
A tabela acima, aponta quais foram os países que receberam publicações dos programas selecionados. Observa-se que Estados Unidos, Inglaterra e Venezuela são os que mais receberam.

\subsection{Internacionalização}

Como ações para internacionalização dos programas em stricto sensu - ou seja, formas de os programas obterem cooperação internacional - a CAPES (2013a) considera 14 indicadores de internacionalização dentro do seu documento de área, que podem ser considerados como estratégias para que as universidades fortaleçam sua rede de cooperação internacional (ver Figura 1). Porém, o alcance geral dos quatro programas analisados na presente pesquisa foi de 10 indicadores, correspondendo a 71,5\% do total sendo que os quatro programas das quatro instituições juntas alcançaram 55 diferentes países.

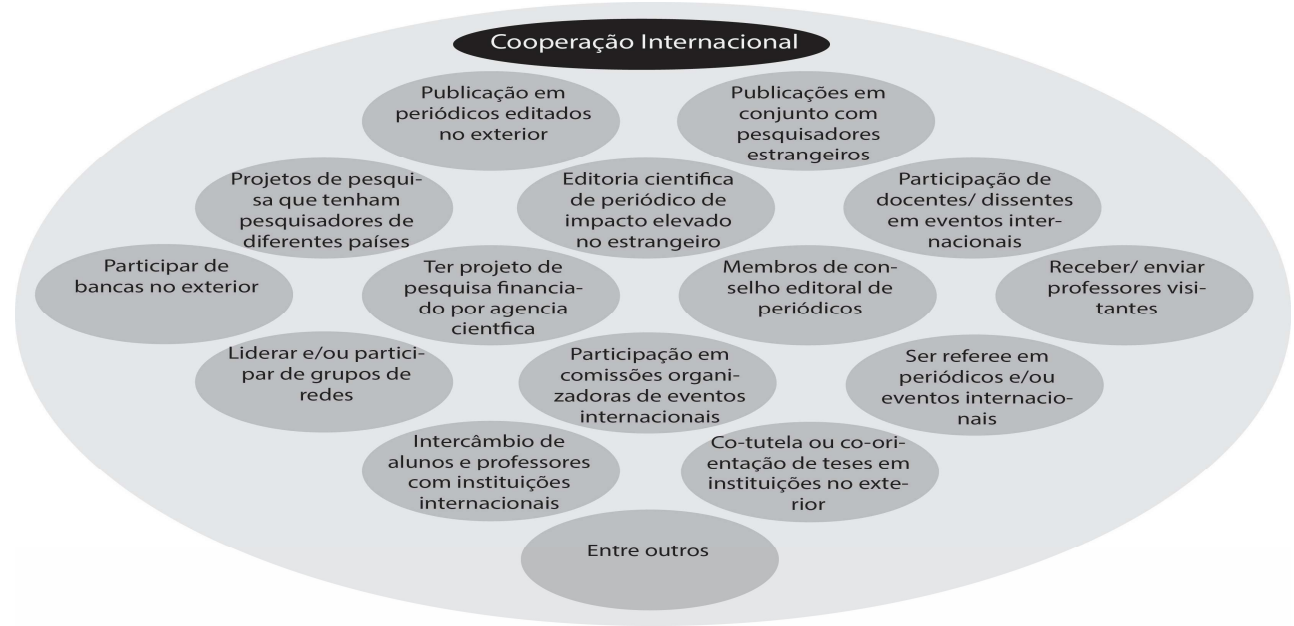

Figura 1- Modelo de cooperação internacional

Fonte: CAPES, 2013a

No que diz respeito ao alcance geral de indicadores dos quatro programas pesquisados (ver Tabela 5), observa-se que o item 8 (intercâmbio de alunos e professores) correspondeu a 367 ações em números, o que representa 38\% do total. Em seguida tem-se o item 1 (publicação) com 249, correspondendo a 26\%. O indicador 10 (outros - ações não especificadas pela CAPES) indicou 100, o que representa $10 \%$ do total. Em quarto lugar está o item 3 (participação de discentes, docentes em eventos internacionais), com 72 ações, o que representa 7\% do total. Em quinto e sexto lugares estão, respectivamente, os itens 6 (receber/enviar professores visitantes) e 5 (membros de conselho editorial), com 47 e 45 ações, cada um representando $5 \%$ do total. O item 9 (cotutela ou co-orientação) apresentou 32 ações, correspondendo a 3\%. Já o item 4 (ter projeto de pesquisa financiado por agência científica) apresentou 27 ações,3\% do total. 0 item 2 (projetos de pesquisa que tenham pesquisadores de diferentes países) aparece com 15 ações, correspondendo a 2\%. Por fim, o indicador 7 (participação em comissões organizadoras de eventos internacionais) apresentou 7 ações, $1 \%$ do total. 
Tabela 5-Indicadores sugeridos pela CAPES dos quatro programas pesquisados (2010-2012)

\begin{tabular}{|c|c|c|c|c|}
\hline № & Indicadores & № & $\%$ & $\begin{array}{c}\text { Países } \\
\text { Diferentes }\end{array}$ \\
\hline 1 & Publicação em periódicos editados no exterior & 249 & $26 \%$ & \\
\hline 2 & Projetos de pesquisa que tenham pesquisadores de diferentes países & 15 & $2 \%$ & \\
\hline 3 & Participação de discentes, docentes em eventos internacionais & 72 & $7 \%$ & \\
\hline 4 & Ter projeto de pesquisa financiado por agência científica & 27 & $3 \%$ & \\
\hline 5 & Membros de conselho editorial de periódicos & 45 & $5 \%$ & \\
\hline 6 & Receber/enviar professores visitantes & 47 & $5 \%$ & 55 \\
\hline 7 & Participação em comissões organizadoras de eventos internacionais & 7 & $1 \%$ & \\
\hline 8 & Intercâmbio de alunos e professores com instituições internacionais & 367 & $38 \%$ & \\
\hline 9 & Cotutela ou co-orientação de teses instituições no exterior & 32 & $3 \%$ & \\
\hline \multirow[t]{2}{*}{10} & Outros & 100 & $10 \%$ & \\
\hline & Total & 961 & $100 \%$ & \\
\hline
\end{tabular}

Fonte: Elaboração própria com base em dados do Caderno de Indicadores (CAPES, 2014a).

A Tabela 6 discrimina cada um dos indicadores por instituição pesquisada no período 2010-2012, apresentando-os em números absolutos de ocorrência de cada um deles e o número de países diferentes relacionados.

Tabela 1 - Apresentação de indicadores das quatro instituições pesquisadas, em números absolutos de ocorrência e por países (2010-2012)

\begin{tabular}{|c|c|c|c|c|c|c|c|c|c|c|}
\hline \multirow{2}{*}{ Indicadores } & \multicolumn{2}{|c|}{ FGV-RJ } & \multicolumn{2}{|c|}{ FGV-SP } & \multicolumn{2}{|c|}{ UFMG } & \multicolumn{2}{|c|}{ USP } & \multicolumn{2}{|c|}{ Geral } \\
\hline & № & Países & № & Países & № & Países & № & Países & № & Países \\
\hline $\begin{array}{l}\text { Publicação em periódicos } \\
\text { editados no exterior }\end{array}$ & 71 & 14 & 72 & 12 & 27 & 12 & 79 & 19 & 249 & 56 \\
\hline $\begin{array}{l}\text { Publicação em conjunto com } \\
\text { pesquisadores estrangeiros }\end{array}$ & - & - & - & - & - & - & - & - & - & - \\
\hline $\begin{array}{l}\text { Projetos de pesquisa que } \\
\text { tenham pesquisadores de } \\
\text { diferentes países }\end{array}$ & 0 & 0 & 7 & 4 & 8 & 6 & 0 & 0 & 15 & 8 \\
\hline $\begin{array}{l}\text { Editoria científica de impacto } \\
\text { elevado no estrangeiro }\end{array}$ & 0 & 0 & 0 & 0 & 0 & 0 & 0 & 0 & 0 & 0 \\
\hline $\begin{array}{l}\text { Participação de discentes, } \\
\text { docentes em eventos } \\
\text { internacionais }\end{array}$ & 0 & 0 & 63 & 3 & 9 & 8 & 0 & 0 & 72 & 9 \\
\hline $\begin{array}{l}\text { Participar de bancas no } \\
\text { exterior }\end{array}$ & 0 & 0 & 0 & 0 & 0 & 0 & 0 & 0 & 0 & 0 \\
\hline $\begin{array}{l}\text { Ter projeto de pesquisa } \\
\text { financiado por agência } \\
\text { científica }\end{array}$ & 9 & 1 & 11 & 2 & 5 & 3 & 2 & 1 & 27 & 6 \\
\hline Membros de conselho & 17 & $3^{*}$ & 28 & $5^{*}$ & 0 & 0 & 0 & 0 & 45 & 7 \\
\hline
\end{tabular}

Revista ADM.MADE, Rio de Janeiro, ano 16, v.20, n.2, p.1-22, maio/agosto, 2016. 


\begin{tabular}{|c|c|c|c|c|c|c|c|c|c|c|}
\hline editorial de periódicos & & & & & & & & & & \\
\hline $\begin{array}{l}\text { Receber/enviar professores } \\
\text { visitantes }\end{array}$ & 40 & 10 & 7 & 5 & 0 & 0 & 0 & 0 & 47 & 11 \\
\hline $\begin{array}{l}\text { Liderar e/ou participar de } \\
\text { grupos de redes }\end{array}$ & 0 & 0 & 0 & 0 & 0 & 0 & 0 & 0 & 0 & 0 \\
\hline $\begin{array}{l}\text { Participação em comissões } \\
\text { organizadoras de eventos } \\
\text { internacionais }\end{array}$ & 0 & 0 & 7 & 2 & 0 & 0 & 0 & 0 & 7 & 2 \\
\hline $\begin{array}{l}\text { Ser referee em periódicos } \\
\text { e/ou eventos internacionais }\end{array}$ & 0 & 0 & 0 & 0 & 0 & 0 & 0 & 0 & 0 & 0 \\
\hline $\begin{array}{l}\text { Intercâmbio de alunos e } \\
\text { professores com instituições } \\
\text { internacionais }\end{array}$ & 172 & 20 & 33 & 9 & 15 & 9 & 147 & 35 & 367 & 42 \\
\hline $\begin{array}{l}\text { Cotutela ou co-orientação de } \\
\text { teses em instituições no } \\
\text { exterior }\end{array}$ & 0 & 0 & 0 & 0 & 30 & $2^{*}$ & 2 & 1 & 32 & 3 \\
\hline Outros & 0 & 0 & 6 & 4 & 0 & 0 & 94 & 6 & 100 & 9 \\
\hline Total & 309 & 31 & 234 & 22 & 94 & 21 & 324 & 42 & 961 & 55 \\
\hline
\end{tabular}

Fonte: Elaboração própria com base em dados do Cadernosde Indicadores(CAPES, 2014a).

*Muitas entradas sem informação do país.

Em relação aos dados apresentados na Tabela 6, é importante destacar que:

a) Em números absolutos, a USP foi a instituição que mais publicou artigos no exterior (79), e a que mais publicou em diferentes países (19);

b) O indicador "Publicação em conjunto com pesquisadores estrangeiros" não foi avaliado na presente pesquisa, porque não há uma base internacional de dados para verificar os laços internacionais;

c) Em números absolutos, a UFMG foi a que mais apresentou projetos de pesquisa que tenham pesquisadores de diferentes países (8), alcançando seis diferentes países com esse indicador. A USP e a FGV-RJ não apresentaram esse indicador;

d) As quatro instituições não tiveram resultados no indicador "Editoria científica de impacto elevado no estrangeiro";

e) Em relação ao indicador "Participação de discentes/docentes em eventos internacionais", a instituição que mais se destacou foi a FGV-SP, com 63 participações, atingindo três diferentes países. Já a UFMG teve nove participações, porém atingiu oito diferentes países;

f) As quatro instituições não tiveram resultados no indicador "Participar de bancas no exterior";

g) Quanto ao indicador "Ter projeto de pesquisa financiado por agência científica", a instituição que mais se destacou foi a FGV-SP, com 11 projetos, atingindo dois diferentes países. Já a UFMG teve cinco projetos, porém atingiu três diferentes países;

h) No indicador "Membros de conselho editorial de periódicos", a instituição que mais se destacou foi a FGV-SP, com 28 docentes, atingindo cinco países diferentes. Em relação a 
esse indicador, é importante destacar que uma grande quantidade de docentes não informou os países de cujos conselhos editoriais são membros;

i) Em relação ao indicador "Receber/enviar professores visitantes", a instituição que mais se destacou foi a FGV-RJ, com o envio/recebimento de 40 professores de/para 10 países distintos. Já a FGV-SP teve sete docentes de cinco países distintos;

j) As quatro instituições não tiveram resultados no indicador "Liderar e/ou participar de grupos de redes";

k) Quanto ao indicador "Participação em comissões organizadoras de eventos internacionais", apenas a FGV-SP apresentou resultados: sete participações em dois países distintos;

1) As quatro instituições não tiveram resultados no indicador "Ser referee em periódicos e/ou eventos internacionais";

m) Em relação ao indicador "Intercâmbio de alunos e professores com instituições internacionais", a FGV-RJ enviou/recebeu 172 alunos e professores, atingindo 20 diferentes países. Já a USP enviou/recebeu 147, atingindo 35 países distintos. A FGV-SP e a UFMG atingiram nove países distintos, enviando/recebendo, respectivamente, 33 e 15 professores/alunos;

n) No indicador "Cotutela ou co-orientação de teses em instituições no exterior", a UFMG apresentou 30 pesquisadores, atingindo dois países (27 deles não informaram o país). Já a USP apresentou duas co-orientações em um país.

No que diz respeito à rede dos indicadores de internacionalização dos quatro programas selecionados, de forma conjunta ela consta no Gráfico 2, onde as linhas representam a conexão entre as instituições e os países para todos os indicadores de internacionalização medidos, e a espessura da linha representa a quantidade de conexões entre as instituições e os países (quanto mais grossa, mais ligações).

\section{CONCLUSÃO}

Considerando que a internacionalização do ensino constitui uma estratégia para que os programas de pós-graduação das universidades se diferenciem uns dos outros, e que esse tema vem assumindo maior relevância no contexto atual, a presente pesquisa identificou o que a CAPES (2013a) considera como indicadores de grau de internacionalização. Também verificou o esforço de atingimento desses indicadores por parte de cada um dos programas stricto sensu em Administração que são considerados com elevado grau de internacionalização, segundo a própria CAPES, na avaliação do triênio 2010-12.

No que diz respeito à formação dos docentes, identificou-se que os quatro programas apresentam todos os seus docentes com pelo menos o doutorado concluído, e que apenas parte deles tem pós-doutorado - dentre esses, em ordem decrescente, a FGV-SP com $42 \%$, a USP com $40 \%$, a UFMG com $36 \%$ e a FGV-RJ com $28 \%$. A USP apresentou o menor percentual de docentes vinculados ao programa que cursou doutorado no exterior $(4,76 \%)$ enquanto a FGV- RJ, a FGV-SP e a UFMG tiveram, respectivamente, $44 \%, 27 \%$ e $4 \%$ de docentes com doutorado no exterior. 


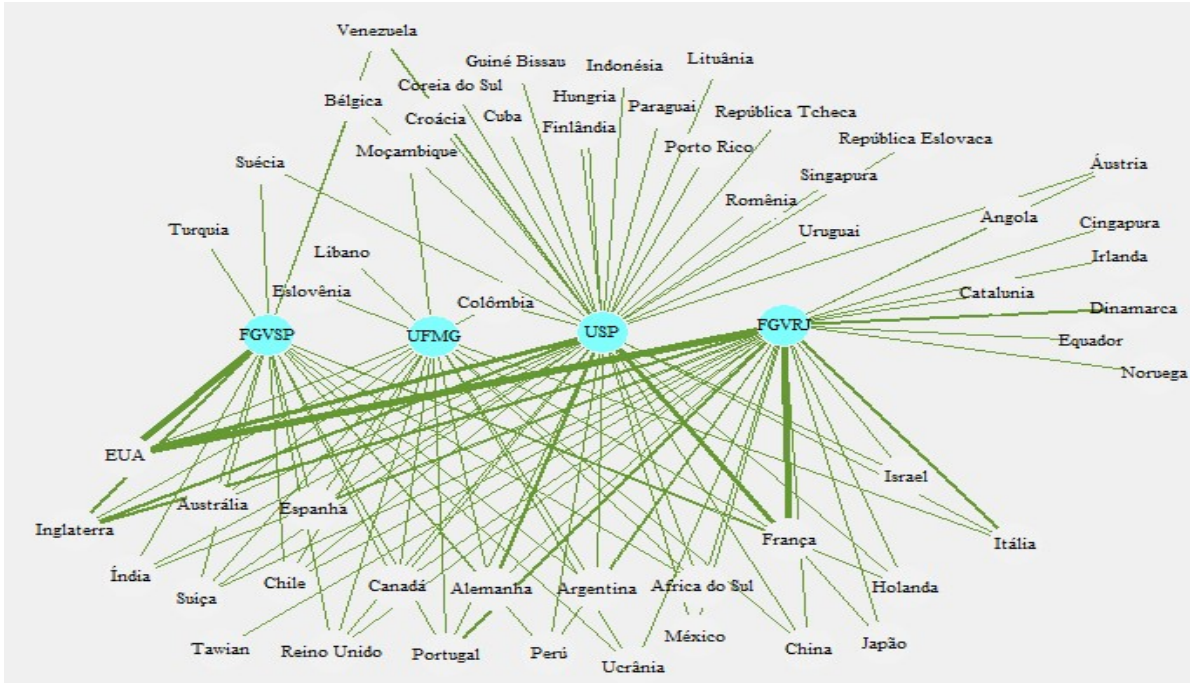

Gráfico 2 - Rede dos indicadores de internacionalização dos quatro programas selecionados - Triênio 2010-12

Fonte: Elaboração própria com base em dados do Cadernos de Indicadores (CAPES, 2014a).

A formação completa ou parcial no exterior pode ser compreendida como uma maior possibilidade de realizar interações com outras instituições e de elevar as ações nos indicadores de internacionalização propostos pela CAPES. Isso porque dá a possibilidade de o docente tanto aumentar a sua rede, quanto ampliar o conhecimento em novos idiomas, o que facilitaria a comunicação entre os docentes e, consequentemente, elevaria a nota dos programas avaliados. Essa formação no exterior pode ser justificada pela análise das publicações, pois a FGV-RJ - instituição que mais apresenta docentes formados no exterior foi também aquela que apresentou percentualmente o maior número de publicações no exterior: $39 \%$, enquanto a FGV-SP, a UFMG e a USP apresentaram, respectivamente, $28,8 \%$, $9,9 \%$ e $21,6 \%$. Entretanto é importante frisar que a USP, apesar de apresentar percentualmente o menor número de artigos publicados no exterior, foi a que apresentou, em números absolutos, a maior quantidade de publicações, tanto no Brasil quanto no exterior. No caso, os países que mais frequentemente receberam publicações do Brasil foram os Estados Unidos e em seguida a Inglaterra, os mesmos onde a maior parte dos docentes das instituições pesquisadas têm formação.

De acordo com os dados coletados e analisados, o inglês é de fato o idioma declarado como o mais utilizado dentro dos critérios disponibilizados pelo currículo Lattes, como leitura, compreensão, fala e escrita, abrangendo $97 \%$ do total de docentes. Em seguida está a língua espanhola, com $82,1 \%$, e em terceiro lugar o francês, com $57,7 \%$. Ressalta-se, ainda, que Venezuela e Espanha são respectivamente o terceiro e o quarto países que mais receberam publicações das instituições. Esse resultado pode indicar que o fato de saber utilizar o idioma pode ser uma ferramenta para conseguir mais interações em países com outro idioma diferente do português. Entretanto, é importante destacar que, especificamente tratando sobre as questões dos indicadores sugeridos pela CAPES para verificar a internacionalização dos programas, foi identificado que não há elevado alcance dos indicadores por todos os programas, tampouco equilíbrio entre eles. Isto é, dos 14 
indicadores sugeridos, o alcance de todos os quatro programas no total foi de 10 , o que corresponde a $71,5 \%$, sendo que os quatro programas das quatro instituições juntas alcançaram 55 diferentes países.

Diversos indicadores não foram informados pelas instituições, como, por exemplo, editoria científica de impacto no estrangeiro, participação em bancas no exterior, liderar ou participar de grupos de redes, e ser referee em periódicos ou eventos internacionais. Outros indicadores foram informados por apenas dois programas, tais como projetos de pesquisas que tenham participação de pesquisadores de diferentes países, participação de discentes e docentes em eventos internacionais, receber e enviar professores visitantes, cotutela ou coorientação em teses em instituições no exterior. O indicador participação em comissões organizadoras de eventos internacionais foi informado apenas pela FGV-SP.

É importante que todos os programas pesquisados intensifiquem seus esforços para cumprir o máximo de indicadores possível. Diversos autores destacam a importância de as universidades buscarem fazer parte do cenário internacional, se destacarem e fortalecerem a imagem da instituição em um mercado fortemente competitivo. Além disso, do ponto de vista acadêmico, nos dias atuais é fundamental unir diferentes pesquisadores para que cada um contribua com suas habilidades e eleve não só a qualidade de o que é produzido, como também a quantidade. Afinal, no Brasil, a quantidade de produção também é um fator a ser avaliado pela CAPES.

Em uma avaliação geral dos indicadores de internacionalização dos quatro programas, verificou-se que o indicador intercâmbio de alunos e professores corresponde a $38 \%$ do total atingido pelos quatro programas (dos 10 que foram cumpridos). Em segundo lugar está o indicador publicação em periódicos editados no exterior, com $26 \%$. Já o indicador outros aparece com $10 \%$, em terceiro lugar geral. Os demais têm participação entre 1 e $7 \%$.

Existe forte diferença no alcance dos indicadores por cada programa pesquisado, tendo o programa em Administração da USP o maior percentual de participação, com $34 \%$ ainda que tenha sido verificado que é a instituição que possui menos docentes com formação total ou parcial no exterior. A FGV-RJ vem em segundo lugar, com 32\%; a FGV-SP em terceiro, com $24 \%$, e a UFMG em quarto, com $10 \%$. É importante ressaltar que, pela avaliação da CAPES no triênio 2010-12, a FGV-RJ e a UFMG obtiveram nota 6, enquanto a FGV-SP e a USP obtiveram nota 7.

\subsection{Limitações da pesquisa}

Diversas dificuldades foram sentidas no acesso aos dados:

1) A falta de base de dados para coletar informações sobre os pesquisadores estrangeiros

2) A ausência de uma base de dados pura para tratar apenas sobre os critérios de internacionalização.

3) A divergência entre o nome do pesquisador informado no documento disponibilizado pela CAPES e o nome encontrado na plataforma Lattes, 
4) O cadastro incompleto de informações no currículo Lattes - nesse último caso, por exemplo, o não preenchimento do ano de publicação de artigos e a não informação sobre a instituição cursada pelo pesquisador.

5) Quanto à informação sobre o idioma, diversos pesquisadores não preencheram completamente as quatro habilidades consideradas pela CAPES: compreende, fala, lê, escreve.

6) A ausência de padronização dos nomes nas citações bibliográficas, o que eleva o grau de dificuldade para saber se se trata do mesmo pesquisador ou se são pessoas diferentes.

7) De forma geral, nem todas as instituições pesquisadas disponibilizaram claramente as suas ações - ou seja, de forma completa ou padronizada: algumas foram mais detalhadas em suas informações e outras pouco precisas.

Tendo em vista que a presente pesquisa focalizou amostra de quatro programas de pós-graduação stricto sensu em Administração, uma vez que restrita apenas àqueles com notas 6 e 7, não foi possível explorar diferentes tipos de análises estatísticas. Além disso, assumiu-se como pressuposto que as universidades encaminharam informações corretas para a CAPES e que todos os pesquisadores vinculados ao programa preencheram seus currículos Lattes de forma completa e correta, além de os atualizarem com frequência.

Finalmente, diversas publicações registradas na presente pesquisa não informavam o Digital Object Identifier (DOI), padrão para identificação de documentos em redes de computadores. Ocorre que o software scriptLattes, utilizado na análise dos dados, filtra as informações sobre coautoria e internacionalização a partir dos currículos dos pesquisadores, sendo, porém, necessário que o pesquisador, ao cadastrar a publicação, informe-lhe o DOI, porque, na sua extração, a ferramenta citada só leva em consideração as publicações que têm essa informação.

\subsection{Sugestões de pesquisas futuras}

Devido às limitações para coleta de dados, como pesquisa futura sugere-se a criação de uma padronização para a informação de cada um dos indicadores apontados pela CAPES, a fim de que os programas não só de Administração, como de outras áreas, forneçam suas informações sobre as ações de internacionalização que realizam de maneira padronizada, facilitando a visualização bem como a avaliação pela CAPES.

Isso também auxiliaria os programas de pós-graduação a evitar erros ou ocultação no envio de informações, pois minimizaria a possibilidade de esquecimento de quem preenche o relatório e a omissão de informações que podem ser relevantes tanto para CAPES quanto para os interessados nessas informações. Para os pesquisadores, poderia facilitar a busca pelas informações, servindo como banco de dados para a realização de pesquisas mais detalhadas sobre a internacionalização dos programas e para a verificação dos indicadores de seu interesse. Sugere-se também que seja ampliado o foco de estudo, abrangendo outras grandes áreas, a fim de contribuir para o conhecimento sobre a internacionalização do ensino stricto sensu no Brasil. 


\section{Referências}

ACEDO, F.; BARROSO, C.; CASANUEVA, C.; GALÁN, J. Co-authorship in management and organizational studies: an empirical and network analysis. Journal of Management Studies, v. 43, n. 5, p. 957-983, 2006.

ALVES, P. S. M. Estruturação, gestão e governança de redes de pequenas e médias empresas: um estudo no varejo farmacêutico da região metropolitana de Belo Horizonte. 96 f. Dissertação (Mestrado em Administração) - Faculdade de Administração, Universidade FUMEC, Belo Horizonte, 2008.

ALVES, J. N. et al. Redes de cooperação de pequenas e médias empresas: os fatores competitivos aplicados em uma rede de imobiliárias. Revista Gestão e Regionalidade, v. 26, n.78, p. 18-35, setdez. 2010.

BENNETT, Roger; KOTTASZ, Rita. Strategic, competitive, and co-operative approaches to internationalisation in European business schools. Journal of Marketing Management, v. 27, n. 1112, p. 1087-1116, October 2011.

BURT, R. S. Structural holes: the social structure of competition. Cambridge, MA: Harvard University Press, 1992.

CAPES - COORDENAÇÃO DE APERFEIÇOAMENTO DE PESSOAL DE NÍVEL SUPERIOR. Apresentação Resultados Trienal 2013. Publicado em 24 de abril de 2014a. Disponível em: <https://drive.google.com/viewerng/viewer?a=v\&pid=sites\&srcid=Y2FwZXMuZ292LmJyfHRyaWVuY WwtMjAxM3xneDo1MmMwNmY3ZTU1ZjBmZGI3>. Acesso em: 14 jan. 2014.

CAPES - COORDENAÇÃO DE APERFEIÇOAMENTO DE PESSOAL DE NÍVEL SUPERIOR. Avaliação Trienal 2013. Publicado em 24 de abril de 2014b. Disponível em: <http://docs.google.com/viewer?a=v\&pid=sites\&srcid=Y2FwZXMuZ292LmJyfHRyaWVuYWwtMjAxM 3xneDo2Yzc3ZTI1ZjA3MTg0ODNi>. Acesso em: 14 jan. 2014.

CAPES - COORDENAÇÃO DE APERFEIÇOAMENTO DE PESSOAL DE NÍVEL SUPERIOR. Cadernos de Indicadores.

Disponível

em:

$<$ http://conteudoweb.capes.gov.br/conteudoweb/CadernoAvaliacaoServlet>. Acesso em: 24 de abril de 2014c.

CAPES - COORDENAÇÃO DE APERFEIÇOAMENTO DE PESSOAL DE NíVEL SUPERIOR. Documento de Área 2013a: Administração, Ciências Contábeis e Turismo. Disponível em: <https://drive.google.com/viewerng/viewer?a=v\&pid=sites\&srcid=Y2FwZXMuZ292LmJyfHRyaWVuY WwtMjAxM3xneDozYTY0OWJkNGU1NWI3Y2Zh>. Acesso em: 27 abr. 2014.

CASTELLS, M. A sociedade em rede. 2 ed. São Paulo: Paz e Terra, 1999.

CHILD, J.; RODRIGUES, S. B. The process of SME internationalization: british firms entering Brazil. Birmingham: Center for International Business and Organization Research - Birmingham Business School, 2005.

CRESWELL, John W. Projeto de Pesquisa. 2. ed. Porto Alegre: Artmed, 2007.

DE WIT, H. Internationalization of Higher Education in the United States of America and Europe: A Historical, Comparative, and Conceptual Analysis. Westport (CT): Greenwood Publishers, 2002.

FREIRE, A. C.; BALDI, M.; LOPES, F. D. Expandindo a análise de redes de inovação: uma reflexão a partir da perspectiva de redes sociais. In: SIMPÓSIO DE GESTÃO DA INOVAÇÃO TECNOLÓGICA ANPAD, 46., Vitória/ES. Anais... Vitória/ES: [s. n.], 28 a 30 de novembro de 2010. Disponível em: <http://www.anpad.org.br/diversos/trabalhos/Simp\%C3\%B3sio/simposio_2010/2010_SIMPOSIO261 .pdf>. Acessoem: 26 mar. 2014. 
GRANDORI, A.; SODA, G. Inter-firm networks: antecedents, mechanisms and forms, Organization Studies, v. 16, n. 2, p. 183-214, 1995.

GRANOVETTER, M. The strength of weak ties. American Journal of Sociology, v. 78, n. 6, p. 13601380, 1973.

HARRIS, S. Internationalising the University. Educational Philosophy and Theory, v. 40, n. 2, p. 346357, 2008.

HORTA, H. Global and national prominent universities: internationalization, competitiveness and the role of the State. High Educ, v. 58, n. 3, p. 387-405, 2009.

HUDSON, J. Trends in multi-authored papers in Economics. The Journal of Economic Perspectives, $v$. 10, n. 3, p. 153-158, 1996.

LEMIEUX, V; OUIMET, M. Análise estrutural das redes sociais. 2. ed. Lisboa: Editora Epistemologia e Sociedade, 2012.

MAAS-GARCIA, L.;TER MATEN-SPEKSNIJDER, A. The Bologna Agreement and its impact on the Master in Advanced Nursing Practice Program at Rotterdam University of Applied Science: incorporating mandatory internationalization in the curriculum. International Nursing Review,v. 56, p. 393-395, 2009.

MATTAR, F. N. Pesquisa de marketing. 3. ed. São Paulo. Atlas: 2000.

MIRANDA, G.J.; SANTOS, L.; CASA NOVA, S.P. C.; CORNACCHIONE JUNIOR, E. B. A pesquisa em educação contábil: produção científica e preferências de doutores no período de 2005 a 2009. Revista Contábil Financeira, USP, São Paulo, v. 24, n. 61, p. 75-88, jan./fev./mar./abr. 2013.

MIURA, I. K. O processo de internacionalização da Universidade de São Paulo: um estudo em três áreas de conhecimento. 379 f. Tese (Livre Docência em Recursos Humanos) - Faculdade de Economia, Administração e Contabilidade de Ribeirão Preto, Universidade de São Paulo - USP, Ribeirão $\quad 2006 . \quad$ Preto, Disponível em: <http://www.teses.usp.br/teses/disponiveis/livredocencia/96/tde-03102006-135941/>. Acesso em: 4 abr. 2014.

RIBEIRO, H. C. M.; CIRANI, C. B. S.; FREITAS, E. J. S. M. Análise da Produção Científica da Revista de Administração e Inovação. In: SIMPÓSIO DE ADMINISTRAÇÃO DA PRODUÇÃO, LOGÍSTICA E OPERAÇÕES INTERNACIONAI - SIMPOI, 14., São Paulo/SP. Anais... São Paulo/SP: Fundação Getúlio Vargas, 28, 29 e 30 de agosto de 2013/Unidade Berrini da FGV.

STALLIVIERI, L. O processo de internacionalização nas instituições de ensino superior. Universidade Caxias do Sul, Dourados/MS, p. 1, 16 abr. 2008. Disponível em: <https://www.ucs.br/ucs/tplCooperacaoCapa/cooperacao/assessoria/artigos/processo_internaciona lizacao.pdf>. Acesso em: 7 abr. 2014. 